\title{
PERANCANGAN APLIKASI PENGOLAHAN DATA OBAT MASUK DAN KELUAR PADA UPTD PUSKESMAS TRIMULYO BERBASIS JAVA
}

\author{
Ahmad Ibnu Mubarok ${ }^{(1)}$ Arif Hidayat ${ }^{(2)}$ \\ Jurusan Ilmu Komputer, Fakultas Ilmu Komputer,Universitas Muhammadiyah Metro \\ Jl.Gatot Subroto No.100 Yosodadi Kota Metro, Telpon:(0725)42445-Fax(0725)42454 \\ E-mail: androidarifhidayat@gmail.com
}

\begin{abstract}
Abstrak
Tugas akhir ini merupakan hasil dari analisa dan observasi yang penulis lakukan terhadap system informasi yang sedang berjalan dan hasil perancangan yang baru pengolahan data obat, pada puskesmas trimulyo kabupaten lampung timur. Secara garis besar penulis dapat mengemukakan bahwa system informasi yang sedang berjalan belum cukup baik karena terdapat kekurangan pada system tersebut, yaitu pengolahan data obat, maupun obat masuk dan obat keluar menggunakan Microsoft excel sehingga pembuatan laporan sering mengalami keterlambatan.Penelitian menggunakan metode pengolahan data berupa observasi, interview, dan dokumentasi, sedangkan metode perancangan system informasi menggunakan Bagan Alir Dokumen, Data Flow Diagram, Entity Relationship Diagram. Softwere pendukung dalam pembuatan aplikasi pengolahan data dengan menggunakan bahasa pemograman NetBeans IDE dan database yang digunakan adalah Database AppServ.

Kata Kunci: Perancangan Aplikasi Pengolahan Data Obat, Masuk Dan Keluar Pada UPTD Puskesmas Trimulyo Berbasis Java.
\end{abstract}

\section{PENDAHULUAN}

Penggunaan teknologi informasi (IT) saat

ini sudah menyebar hampir di semua

bidang tidak terkecuali di tempat

pelayanan masyarakat. Karena dengan

menggunakan komputer, pekerjaan yang

akan dikerjakan dapat dilaksanakan

dengan mudah, cepat, tepat dan praktis.
Komputer juga dapat mempermudah

manusia dalam melakukan pekerjaanyang sulit, rumit dan butuh ketelitian, maka dengan bantuan komputer pekerjaan tersebut akan mengurangi kesalahan, keterlambatan kerja dan human error. Masyarakat merupakan pelaku dan penggerak dari pembangunan nasional. 
Masyarakat yang sehat merupakan salah satu kunci suksesnya pembangunan nasional, dan undang- undang republik Indonesia nomer 36 tahun 2009 tenteng kesehatan pasal 8 tentang hak dan kewajiban setiap orang berhak memperoleh informasi tentang data kesehatan dirinya termasuk tindakan dan pengobatan yang telah maupun yang diterima dari tenaga kesehatan. Puskesmas trimulyo merupakan pelayanan kesehatan masyarakat di tingkat kecamatan yang beralamat di Jl. Raya Hargomulyo kec.sekapung kab.lampung timur, Puskesmas Trimulyo berdiri pada Tahun 1991 yang awalnya berupa Puskesmas pembantu yang bertempat di Jl. Raya Desa Trimulyo. Pada tanggal 18 Agustus 2000, menjadi puskesmas induk, Adapun bangunan Puskesmas Trimulyo berdiri diatas tanah Eigendom (Milik kas desa). Puskesmas trimulyo sudah di kepalai lebih dari 5 orang yang menjabat sebagai kepala puskesmas, dan saat ini puskesmas trimulyo di kepalai oleh Siti Rokhaniyah. Amd.keb,. wilayah kerja puskesmas trimulyo meliputi 9 (Sembilan) desa yaitu Desa Trimulyo, Desa Sukoharjo, Desa Wonokarto, Desa Girikarto, Desa Hargomulyo, Desa Sumbersari, Desa Mekarmulyo, Desa Jadimulyo, Desa Mekarsari. Pengolahan data obat masih dilakukan secara manual memiliki banyak kekurangan, seperti data obat yang tidak valid ketika data yang masuk salah. Kekurangan lain dari pengambilan data secara manual adalah hilang atau rusaknya data yang ada. Kekurangan lain adalah kurangnya efisiensi dan efektifitas pada pengolahan data. Perkembangan teknologi di dunia semakin pesat, khususnya kemajuan di bidang teknologi informasi terutama pada teknologi mobile dan internet. "Bergembiralah wahai Uтmи 'Ala. Sesungguhnya penyakit yang 
عزّوج diderita seorang Muslim, Allah

nakan menghapuskan dosa-dosanya dengan itu, sebagaimana nyala api menghilangkan kotoran dari emas dan perak"(HR. Abu Dawud). $\quad$ Di

puskesmas trimulyo dalam pengolahan data obat masih di catat pada buku(untuk arsip) dan menggunakan Microsoft Excel (untuk membuat laporan data obat). Adapun permasalah yang ditemui yaitu: a) sering terjadi kesalahan dalam pengolahan daa persediaan obat, di karnakan terlalu banyak arsip, b) petugas gudang obat mengalami keterlambatan dalam pembuatan laporan data obat masuk maupun obat keluar, karena data yang di olah terlalu banyak dan tidak terorganisasi dengan baik. Berdasarkan latar belakang dan permasalahan yang di temui pada tempat penelitian. Oleh karena maka dalam penulisan judul Tugas Akhir penulis mengambil judul "PERANCANGAN APLIKASI
PENGOLAHAN DATA OBAT MASUK DAN KELUAR PADA UPTD

PUSKESMAS TRIMULYO BERBASIS JAVA".

\section{KAJIAN PUSTAKA DAN LANDASAN TEORI}

\section{1 Definisi Perancangan}

Menurut Bentley dan Whitten (2009:160) melalui buku yang berjudul "system analysis and design for the global enterprise" juga menjelaskan bahwa perancangan sistem adalah teknik pemecahan masalah dengan melengkapi komponen-komponen kecil menjadi kesatuan komponen sistem kembali ke sistem yang lengkap. Teknik ini diharapkan dapat menghasilkan sistem yang lebih baik. Menurut Al-Bahra Bin Ladjamudin dalam bukunya yang berjudul Analisis \& Desain Sistem Informasi (2005:39),menyebutkan 
bahwa: "Perancangan adalah suatu kegiatan yang memiliki tujuan untuk mendesign sistem baru yang dapat menyelesaikan masalah-masalah yang dihadapi perusahaan yang diperoleh dari pemilihan alternatif sistem yang terbaik." Menurut jurnal yang ditulis oleh Utami Dewi Widianti (2012) "Perancangan dapat didenifisikan sebagai penggambaran, perencanaan dan pembuatan sketsa atau pengaturan dari beberapa elemen yang terpisah ke dalam satu kesatuan yang utuh dan berfungsi. Tahapan ini menyangkut mengkonfigurasi dari komponenkomponen perangkat lunak dan perangkat keras dari suatu sistem sehingga setelah instalasi dari sistem akan benar-benar memuaskan dari rancang bangun yang telah ditetapkan pada akhir tahap analisis sistem". Dari definisi diatas dapat disimpulkan perancangan adalah suatu tahapan dalam mendesign suatu aplikasi untuk menyelesaikan masalah-masalah yang dihadapi perusahaan.

\subsection{Definisi Aplikasi}

Menurut Budiharto (2013:5) yang dikutip Agustini Putri Lestari (2016) “aplikasi (applications) merupakan program yang dapat berjalan di komputer tersendiri (stand alone computer), dari program yang simple sampai dengan program besar dan rumit”. Dalam buku "Analisis dan Desain Sistem Informasi" menurut Jogiyanto Hartono (2006:12) yang dikutip Triska Apriyani (2015) mendefinisikan bahwa "Perangkat lunak aplikasi (Application) yaitu program yang ditulis dan diterjemahkan oleh language software untuk menyelesaikan suatu aplikasi tertentu". Dalam buku "Analisis dan Desain Sistem Informasi” menurut Jogiyanto Hartono (2006:12) yang dikutip Triska Apriyani (2015) 
mendefinisikan bahwa "Perangkat lunak aplikasi (Application) yaitu program yang ditulis dan diterjemahkan oleh language software untuk menyelesaikan suatu aplikasi tertentu".

Dari definisi diatas dapat disimpulkan bahwa aplikasi adalahsuatu program komputer yang dapat digunakan untuk mengerjakan dan melaksanakan tugastugas dari pengguna dengan tujuan mendapatkan hasil yang akurat sesuai dengan tujuan pengguna tersebut.

\subsection{Definisi Data}

Data berasal dari bahasa latin, datum (tunggal), pemberian, karunia, sajian; data (jamak), hadiah-hadiah, sajian-sajian. Untuk lebih memahami definisi tentang data berikut beberapa pendapat yang dikemukakan oleh para ahli antara lain: Kadir (2009:3) yang dikutip Triska
Apriyani (2017) mendefinisikan data adalah "Fakta-fakta mentah yang mewakili kejadian-kejadian yang berlangsung dalam organisasi atau lingkungan fisik sebelum ditata dan diatur ke dalam bentuk yang dapat dipahami dan di gunakan orang". Hartono (1999:2) yang dikutip Triska Apriyani (2017) "Data adalah kumpulan kejadian yang diangkat dari suatu kenyataan berupa angka-angka, huruf-huruf, atau simbolsimbol khusus atau gabungan darinya yang masih belum bisa bercerita banyak, sehingga perlu diolah lebih lanjut". Dari beberapa definisi diatas dapat disimpulkan bahwa data adalah suatu kejadian yang diangkat dari suatu kenyataan (fakta) dapat berupa angkaangka, huruf, simbol-simbol tertentu, atau gabungan dari ketiganya. Data belum dapat ditafsirkan sehingga perlu diolah agar menghasilkan informasi untuk pengambilan suatu keputusan. 


\subsection{Definisi Pengolahan Data}

Menurut Jugiyanto Hartono (2006:8)

yang dikutip Triska Apriyani (2017) dalam buku "Pengenalan Komputer" menyebutkan bahwa "Pengolahan data adalah manipulasi dari data ke dalam bentuk lebih berguna dan lebih berarti berupa suatu informasi dengan menggunakan suatu alat elektronik yaitu komputer". Dalam buku Jogiyanto (1992:2) yang dikutip Triska Apriyani (2017) yang berjudul "Pengenalan Komputer" menyebutkan bahwa "Pengolahan data adalah manipulasi dari data kedalam bentuk yang lebih berguna dan lebih berarti, berupa suatu informasi." Terdapat siklus pengolahan data yang terdiri dari 3 tahap yaitu dapat dilihat pada gambar 1.1. di bawah ini.

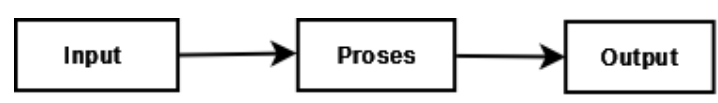

Gambar 2.1. Tampilan Siklus

Pengolahan Data (Sumber Jogiyanto 1999:3)

Data merupakan suatu kejadian yang menggambarkan kenyataan yang terjadi yang dimsukkan dalam elemen input dan kemudian akan diproses menjadi output sehingga menghasilkan informasi yang dibutuhkan. Berdasarkan buku Warren Carl S. (2009:332) yang berjudul “Accounting Pengantar Akuntansi” menyebutkan bahwa "Pengolahan Data adalah waktu yang digunakan untuk menggambarkan bentuk data menjadi informasi yang memiliki kegunaan". Dari pengertian diatas dapat disimpulkan bahwa Pengolahan Data adalah cara mengolah bahan nyata untuk dijadikan dasar kajian, dan data itu akan di olah menjadi informasi yang berguna.

\subsection{Pengertian Obat}


Obat adalah benda atau zat yang dapat di gunakan untuk merawat penyakit, membebaskan gejala, atau mengubah proses kimia dalam tubuh. Obat ialah suatu bahan atau padua bahan-bahan yang dimasukan untuk digunakan dalam mentapkan diagnosis, mencegah, mengurangkan, menghilangkan, menyembukah penyakit atau gejala penyakit, luka atau kelainan badaniah dan rohaniah pada manusia atau hewan dan untuk memperelok atau memperindah badan atau bagian bdan manusia termasuk obat tradisional Obat herbal da nada yang telah melalui proses kimiawi atau fisika tertentu serta telah di uji khasiatnya. Yang trakhir inilah yang lazim dikenal sebagai obat. Obat harus sesui dosis agar efek trapi atau khasiatnya bias kita dapatkan

\subsection{Pengertian Puskesmas}

Pusat Kesehatan Masyarakat, disingkat Puskesmas, adalah organisasi fungsional yang menyelenggarakan upaya kesehatan yang bersifat menyeluruh, trpadu merata, dapat di terima dan terjangkau oleh masyarakat, dengan peran serta aktif mesyarakat dan menggunakan hasil pengembangan ilmu pengetahuan dan teknologi tepet guna, dengan biaya yang dapat dipikul oleh pemerintah dan masyarakat. Puskesmas merupakan unit pelaksana teknis kesehatan di bawah supervise dinas kesehatan kabupaten /kota, secara umum, mereka harus memberikan pelayanan preventif, promotif, kuratif sampai dengan rehabilitative baik melalui upaya kesehatan program (UKP) atau upaya kesehatan masyrakat (UKM), Puskesmas dapat memberikan pelayanan rawat jalan dan rawat inap.

\subsection{Bahasa Pemograman (Java)}

Dalam buku pengenalan java (2015) Java adalah suatu teknologi di dunia software 
komputer, yang merupakan suatu bahasa

pemrograman, dan sekaligus suatu

platform. Sebagai bahasa pemrograman,

Java dikenal sebagai bahasa

pemrograman tingkat tinggi. Java mudah

dipelajari, terutama bagi programmer

yang telah mengenal $\mathrm{C} / \mathrm{C}++$. Java

merupakan bahasa pemrograman

berorientasi objek yang merupakan

paradigma pemrograman masa depan.

Sebagai bahasa pemrograman Java

dirancang menjadi handal dan aman. Java

juga dirancang agar dapat dijalankan di

semua platform. Dan juga dirancang

untuk menghasilkan aplikasi - aplikasi

dengan performansi yang terbaik, seperti

aplikasi database Oracle 8i/9i yang core-

nya dibangun menggunakan bahasa

pemrograman Java. Sedangkan Java

bersifat neutral architecture, karena Java

Compiler yang digunakan untuk

mengkompilasi kode program Java

dirancang untuk menghasilkan kode yang netral terhadap semua arsitekture perangkat keras yang disebut sebagai Java Bytecode. Andi (2012:2) yang dikutip Triska Apriyani (2017) "Java adalah suatu jenis pemrograman yang dikembangkan oleh Sun Microsystem. Teknologi java dapat digunakan untuk pembuatan database, web, jaringan, ataupun grafis".

\subsection{Sejarah Singkat Java}

Java lahir dari sebuah green project yang berjalan selama 18 bulan yaitu pada awal 1991 sampai musim panas 1992. Proyek yang dimotori oleh Pratrick Naugton, Bill Joy, James Gosling, dan sembilan pemrogram lainya dari tim Sun Microsystem yang pada awalnya membuat bahasa pemrograman kecil yang akan diterapkan pada peralatan elektronik. Bahasa pemrograman ini kemudian diberi nama Oak yang merupakan nama salah satu jenis pohon 
yang tumbuh diluar jendela pemimpin proyek tersebut. Bahasa pemrograman Oak merupakan modifikasi dari $\mathrm{C}++$ tetapi lebih mudah beradaptasi pada berbagai sistem operasi dan platform. Seperti yang telah dibuktikan oleh pengembang $\mathrm{C}++$, bahasa pemrograman baru ini lebih kuat tetapi telah memasukkan banyak fitur yang dimiliki $\mathrm{C}++$. Bahasa Oak berganti nama menjadi java setelah bergantinya cara pelayanan konsumen peralatan electronik dari pelayanan manual ke pelayanan online kemudian tim Sun Microsystem mengganti bahasa pemrograman dekstop mejadi web browser. Web browser yang dirilis pada Maret 1995 ini diberi nama HotJava karena Oak sudah digunakan untuk merek dagang perangkat lunak yang telah dikembangkan terlebih dahulu. Maka, nama HotJava-lah yang digunakan unutk versi liris perangkat lunak buatan Sun Microsystem yang berjalan pada web.
Nama ini diambil dari nama kopi murni gilingan langsung (kopi tubruk) kesukaan James Gosling. Tampilan logo java dapat dilihat pada gambar 1.2.

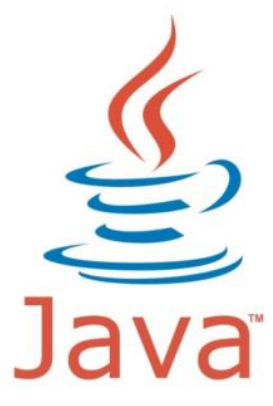

Gambar 2.2. Logo Java (Sumber: Google)

\section{METODE}

Metodelogi adalah kesatuan metodemetode, prosedur, konsep-konsep, pekerjaan, atau aturan yang digunakan oleh suatu ilmu pengetahuan. Dalam memperoleh data guna menyusun Tugas Akhir, penulis menggunakan metodemetode yaitu sebagai berikut:

- Studi Lapangan

Studi lapangan adalah pengumpulan data dan informasi dari tempat penelitian, atas masalah yang sedang dihadapi. Adapun studi lapangan yang penulis lakukan adalah dengan teknik :

- Wawancara (Interview) 
Interview adalah metode pengumpulan data dengan cara wawancara atau tanya jawab secara langsung dengan petugas apoteker yang bersangkutan dengan ini penulis melakukan wawancara secara langsung dengan Ibu Rina selaku Kepala Bagian Farmasi. Terlampir tabel wawancara.

- Pengamatan (Obsevasi)

Observasi adalah metode pengumpulan data dengan cara pengamatan langsung kegiatan operasional yang berlangsung di Puskesmas trimulyo. Terlampir dokumentasi foto.

Dokumentasi (documentation)

- Dokumentasi adalah metode pengumpulan data dengan cara mengambil gambar danmengumpulkan dokumen atau arsip yang dibutuhkan untuk penelitian. Terlampir dokumendokumen.

- Studi Pustaka

Studi pustaka yang penulis lakukan untuk menambahkan beberapa hal yang tidak penulis dapatkan dalam studi lapangan. Dengan cara mengumpulkan data dengan membaca buku-buku yang mempelajari literature yang berkaitan dengan masalah yang dihadapi.

\section{PEMBAHASAN}

\subsection{Hasil penelitan}

Dari hasil penelitian yang dilaksanakan di Puskesmas Trimulyo kabupaten lampung timur msalah pengolahan data persediaan obat yaitu pengolahan data pesedian obat, obat masuk dan obat keluar Di puskesmas trimulyo dalam pengolahan data obat masih di catat pada buku(untuk arsip) dan menggunakan Microsoft Excel (untuk membuat laporan data obat). Adapun permasalah yang ditemui yaitu: a) sering terjadi kesalahan dalam pengolahan daa persediaan obat, di karnakan terlalu banyak arsif, b) petugas gudang obat mengalami keterlambatan dalam pembuatan laporan data obat masuk maupun obat keluar, dikarnakan data yang di olah terlalu banyak dan tidak terorganisasi dengan baik. Penulis melakukan penelitian pengolahan data persedian obat pada bagian gudang obat pada puskesmas trimulyo lampung timur menemukan perumusan masalah antara lain, membuat aplikasi pengolahan data Obat masuk dan obat keluar pada Puskesmas Trimulyo, pembuatan laporan 
dan pencarian persedian obat, obat masuk dan obat keluar di bagian gudang agar lebih cepat dan efisien, agar hasil peneitian yang di lakukan tidak menyimpang dari permasalahan, penulis membatasi ruang lingkup penelitiaannya antara lain, Perancangan aplikasi pengolahan data obat masuk dan obat keluar pada Puskesmas Trimulyo menggunakan bahasa pemograman Java Standart Edition (SE), Database AppServ, Design dengan NetBeans IDE 8.0, pembuatan laporan dan pencarian persedian obat (stok obat), obat masuk dan obat keluar laporan yang dibuat setiap bulan dan perhari.

\subsection{Perancangan Aplikasi}

Dalam perancangan suatu program perlu beberapa tahap untuk menentukan arah dari program tersebut. Sama dengan penulis lakukan dalam pembuatan aplikasi ini, di mulai dari pengumpulan data, analisa system, menentukan dan membuat alus system, membuat relasi tabel, membuat database, merancang tampilan program, sampai pada hasil pemnuatan program (output). Berdasarkan analisa system di peroleh pengolahan data persediaan data obat pada puskesmas Trimulyo sebagai berikut

\section{Tujuan Perancangan Sistem}

Tujuan perancangan aplikasi ini adalah mengurangi terjadinya kesalahan dalam pengolahan data persediaan data obat, pada bagian gudang obat puskesmas trimulyo, perancangan di usulkan sebagai bahan yang dapet di pertimbangkan untuk mrningkatkan efektifitas kinerja khususnya petugas gudang obat.

\section{Kegunaan Perancangan Sistem}

Kegunaan perancangan system yaitu untuk membuat aplikasi pengolahan persediaan data obat yang baik, pada puskesmas Trimulyo, untuk membuat laporan data persedian obat, obat masuk dan obat keluar di bagian gudang agar lebih cepat dan efisien, mempermudah mancari pencarian persediaan data obat, agar lebih cepat dan mudah dilakukan.

\section{Gambaran Umum Sistem} Yang Diusulkan 
System informasi yang di usulkan memiliki beberapa dari system yang sedang berjalan. System yang akan dibuat lebih mudah digunakan, mempermudah menginput data persediaan data obat yaitu meliputi : persedian obat, obat masuk dan obat keluar serta pembuatan laporan cetak laporan perbulan.

4. Perancangan Prosedur Yang Di Usulkan

Pada tahap perancangan prosedur ini berujuan untuk menghasilkan perancangan aplikasi pengolhan data persediaan data obat menggunakan database. Adapun perancangan proses ini mencakup alisan system informasi, diagram konteks, data flow diagram, flowchart yang dapat menjelaskan aliran data yang di proses hingga menghasilkan informasi yang di inginkan.

\section{Kebutuhan Sumber Daya}

\begin{abstract}
Besarnya kapasitas penyimpanan dapat dihitung berdasarkan file-file database yang akan menyimpan data untuk priode tertentu.
\end{abstract}

\section{Perangkat Keras (Hardware)}

Rancangan hardware yang diusulkan penulis untuk dipergunakan dalam implementasi system yang di rancang adalah :
a. Procecor intel inside
b. Memory (RAM) $2 G B$
c. Hard Disk $500 \mathrm{~GB}$
d. Keyboard
e. Monitor
f. Printer

\section{Perangkat Lunak (software)}

Pada rancangan ini penulis menggunakan bebrapa perangkat lunak yang mendukung dalam pengolahan data obat. Adapun spesifikasi prangkat lunak yang digunakan yaitu :
a. System Oprasi Microsoft Windows 10
b. NetBeans IDE 8.0
c. AppServ
d. iReport

\section{Perangkat Pikir}


aplikasi yang sudah di rancang di tunjukan untuk petugas gudang obat sebagai administrator persediaan obat bertugas menginput persediaan obat, obat masuk dan obet keluar.

\section{Aliran Sistem Yang Di Usulkan}

Rancangan aliran informasi persediaan data obat dan pembuatan laporan yang di usulkan sebgai berikut : Petugas gudang obat mencatat peresediaan obat yang ada di gudang obat, setalah itu persediaan data obat di input ke program kemudian di proses cetak laporan persediaan data obat, kemudian membuat permintaan surat obat, lalu laporan persediaan data obat di arsipkan sedangkan surat permintaan obat di berikan ke kepala puskesmas untuk menandatangi surat permintaan obat, selanjutnya surat permintaan obat yang sudah di tandatangi di kembalikan ke gudang obat untuk mengirimkan surat permintaan obat $\mathrm{k}$ dinas kesehatan, kemudian dinas kesehatan mengirim obat dan data obat ke puskesmas, setelah itu obat dan data obat di terima oleh kepala puskesmas, kemudian kepala puskesmas menyerahkan obat dan data obat ke petugas gudang obat, untuk mengecek apakah obat sesui dengan permintaan obat, jika tidak sesuai dengan permintaan obat, maka data obat di kembalikan ke dinas kesehatan sedangkan jika sesuai maka data obat di inputkan ke program dan kemudian di cetak menjadi obat masuk dan di arsipkan, sedangkan obatobatan di simpan di gudang obat, lalu petugas gudang obat mengeluarkan obat ke apotik dan menginput obat yang di keluarkan ke program menjadi data obat keluar, kemudian laporan data obat di berikan $\mathrm{k}$ kepala puskesmas sedangkan obat di berikan ke apotik.

\section{Rancangan bagan alir dokumen} (Flowchart)

Pada tabel 4.1 yaitu rancangan bagian alir dokumen (flowchart) merupakan menjelaskan rancangan bagan alir, dokumendokumen, proses-proses serta pihak-pihak bagan alir dokumen yang terlibat di dalamnya. 
Jurnal Mahasiswa IImu Komputer (JMIK)

Vol. 01, No. 01, Maret 2021

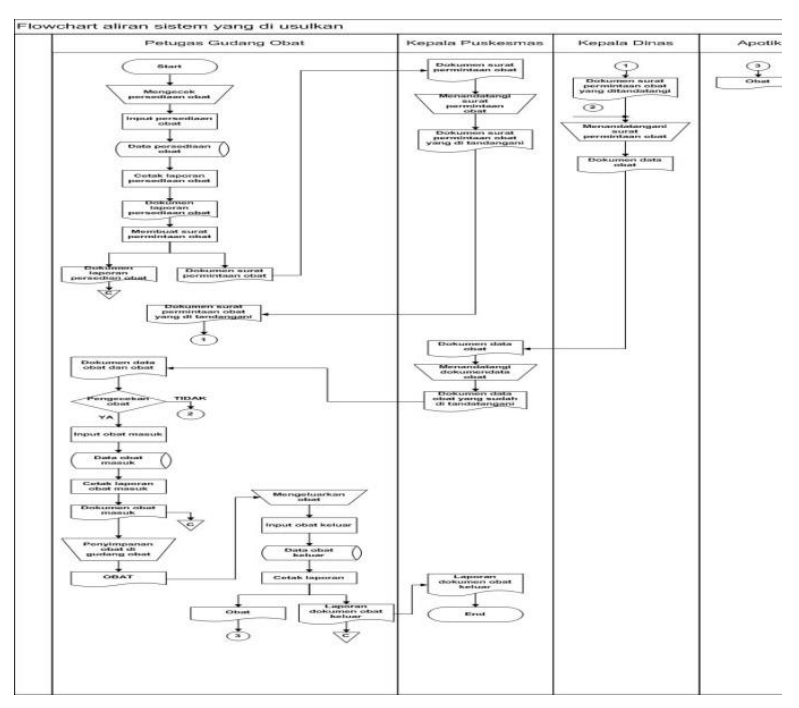

Tabel 4.1 Rancangan Bagian Alir

Dokumen (Flowchart) yang diusulkan

\section{Rancangan Diagram Conteks level 0}

Pada Rancangan Diagram Conteks meliputi data persediaan, obat masuk, dan obat keluar Gambar 4.1 berikut ini menggambarkan rancangan diagram konteks persediaan obat pada Puskesmas Trimulyo.
Gambar 4.1 Rancangan Diagram

Conteks

\section{Rancangan Data Flow Diagram level 1 \\ Pada gambar 4.2} merupakan Rancangan Data Flow Diagram dan penjelasan lebih rinci dari diagram konteks sebelumnya.

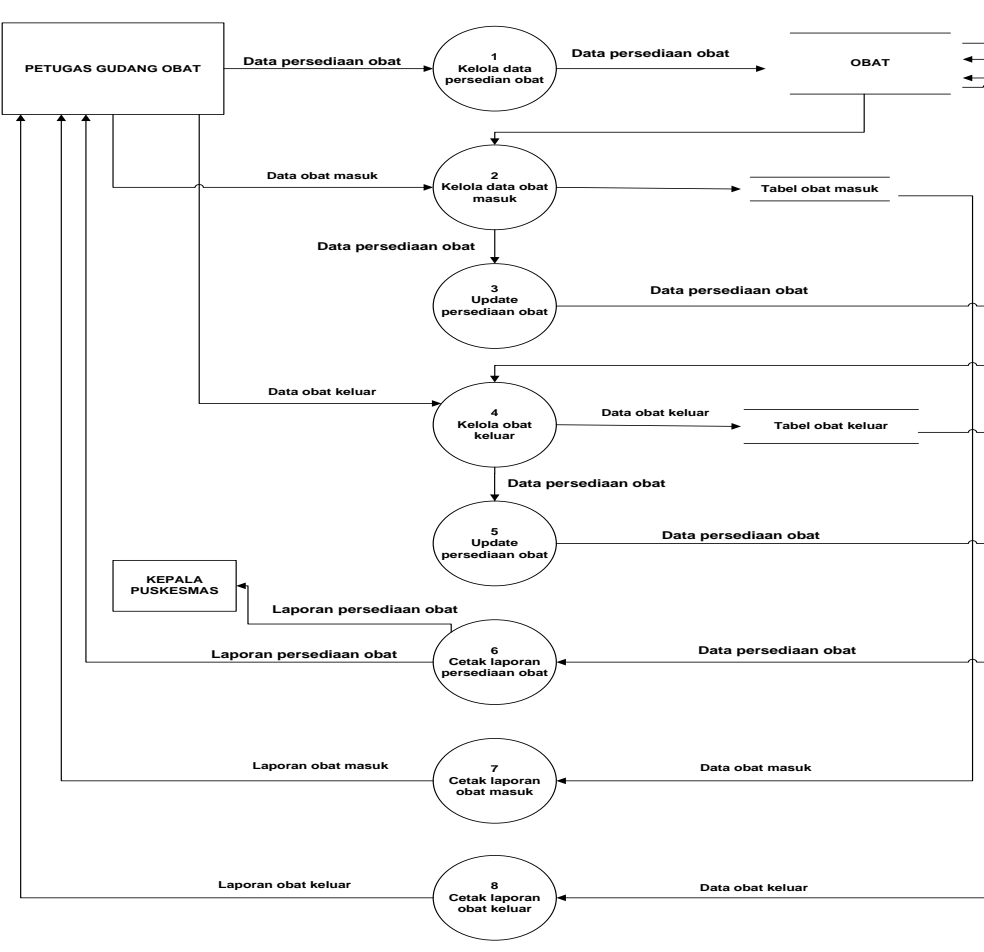

Gambar 4.2 Rancangan Data Flow

Diagram

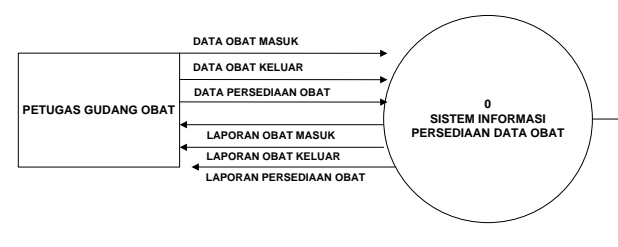

LAPORAN PERSEDIAAN OBat $\rightarrow$ KEPALA PUSKESMAS

\section{Rancangan File/Basis data}

Basis data adalah mekanisme yang digunkan untuk menyimpan 
inforamsi atau data. Dengan basis data, pengguna dapat menyimpan data secara trorganisasi. Setelah data disimpan, informasi harus mudah diambil. Cara data di simpan dalam basis data menentukan seberapa mudah mencari informasi berdasarkan banyak kriteria, data pun harus mudah di tambahkan kedalam basis data, dimodifikasi, dan dihapus. Untuk menyimpan data obat masuk, obat keluar dan persediaan obat pada puskesmas pekalongan kabupaten lampung timur di perlukan sebuah database. Nama Database : d_puskesmas

Isi Database : obat, obatmasuk, obatkeluar

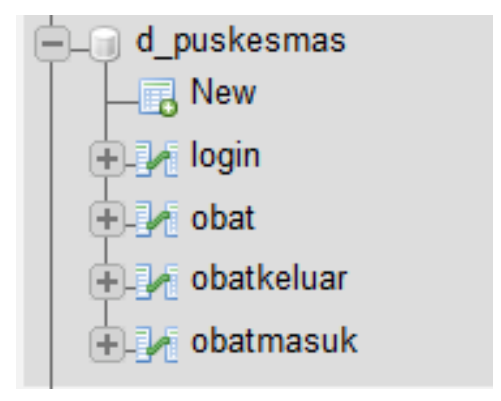

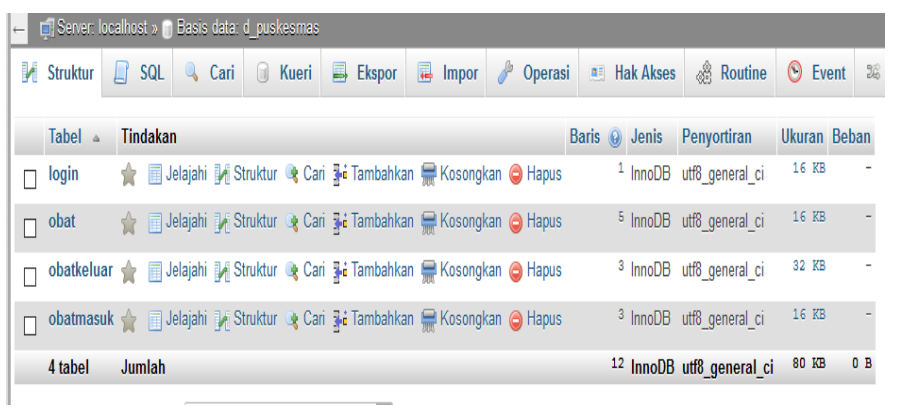

Gambar 4.3 gambar database dan tabele

\section{a. Tabel persediaan obat}

Tabel laporan persediaan obat ini berfungsi untuk menyimpan data persediaan obat yang ada di gudang obat di puskesmas, berikut ini adalah struktur tabelnya :

Nama tabel : obat

Primary key : id_obat

Jumlah field : 4

Tabel 4.2 Tabel persediaan obat

\begin{tabular}{|l|l|l|l|}
\hline Field nama & Type & Size & Keterangan \\
\hline Id_obat & Int & 10 & Id obat \\
\hline Nama_obat & Varchar & 25 & $\begin{array}{l}\text { Primary } \\
\text { key }\end{array}$ \\
\hline Satuan & Varchar & 25 & Nama obat \\
\hline Stok & Date & & $\begin{array}{l}\text { Tanggal } \\
\text { persediaan }\end{array}$ \\
\hline
\end{tabular}

\section{b. Tabel obat keluar}

Tabel 4.3 yaitu yang di gunakan untuk mengetahui permintaan 
obat, seperti pada tabel 4.4

berikut ini :

$$
\begin{array}{ll}
\text { Nama tabel } & \text { :obatkeluar } \\
\text { Primary key } & : \text { id_obat } \\
\text { Jumlah field } & : 7
\end{array}
$$

Tabel 4.3 tabel obat keluar

\begin{tabular}{|l|l|l|l|}
\hline Field nama & Type & Size & Keterangan \\
\hline Id & int & 10 & Id obat \\
\hline id_obat & int & 10 & $\begin{array}{l}\text { Foreigh } \\
\text { key }\end{array}$ \\
\hline Nama_obat & Varchar & 30 & Nama obat \\
\hline Satuan & Varchar & 20 & Jenis \\
\hline Tanggal & Date & & Waktu \\
\hline Stok & Int & 10 & Jumlah \\
\hline Keterangan & Varchar & 30 & Keterangan \\
\hline
\end{tabular}

\section{KESIMPULAN}

\section{Kesimpulan}

Dari hasil penelitian pada puskesmas trimulyo kabupaten lampung timur dapat di ambil kesimpulan yaitu :

- Dalam pembuatan aplikasi penulis menggunakan bahasa pemograman Java Standart Edition (SE), Database MySQL, Design dengan NetBeans IDE 8.0

- Program aplikasi yang penulis buat ini mempermudah petugas gudang obat dalam pembuatan laporan persediaan obat, obat masuk dan obat keluar perbulan lebih cepat,Selain itu Dengan adanya aplikasi pengolhan data obat masuk dan obat keluar dapat mempermudah pencariaan data obat.

\section{Saran}

Dari hasil penelitian pada puskesmas trimulyo kabupaten lampung timur dapat di ambil kesimpulan :

- System yang baru hendaknya di kembangkan agar meningkatkan kualitas pengolahan data obat masuk obat keluar pada gudang puskesmas pekalongan.

- Perwatan terhadap system perlu di perhatikan agar system dapat beroperasi secara maksimal.

- Perlu adanya oprator dalam pengoprasian aplikasi,agarmempermudah pekerjaan petugas dalam pengolahan data obat masuk dan keluar.

\section{DAFTAR PUSTAKA}

[1] Oktafiani Dewi. 2010. Analisis danPerancangan Sistem Informasi Penjualan Obat Pada Apotek 
PrimadonaPalembang.Yogyakarta:AMIK

$\mathrm{OM}$

$$
\text { Riyanto.2011. }
$$

Sistem

InformasiPenjualan dengan Php dan My

Sql.Yogjakarta:

Enterprise, Jubilee. 2015. Mengenal Java dan Database dengan NetBeans. Yogyakarta: PT. Elex Media Komputer.

[3] Kadir, Abdul. 2012. Algoritma \& Pemrograman menggunakan Java. Yogyakarta: Andi Offset.

[4] Supriyanto. 2010. Pemrograman DatabaseMenggunakan Java \& MySQL untuk pemula.Jakarta: Mediakita.

[5] Rosa A.S dan Shalahuddin M, 2013, Rekayasa Perangkat Lunak Terstruktur dan Berorientasi Objek, Bandung: Penerbit Informatika

[6] Jogiyanto, 2009, Analisis Dan Desain, Yogyakarta : Penerbit Andi.

[7] Wahana Komputer. 2012. Membangun Aplikasi Bisnis dengan Netbeans 7. Semarang: Andi Offset.Ardiansyah,
[8] Muhamad dan Herlawati. 2015. Sistem Informasi Penjualan Barang Berbasis Web Pada Toko HENNY'S Butik Bekasi. Jurnal diambil dari Jurnal Sistem Informasi STMIK Antar Bangsa. Vol. IV No.1 Februari 2015. ISSN 2089- 8711. 